\title{
Round Robin Study on Residual Stresses Using X-Ray Diffraction for Shot-Peened Tool Steel Specimens
}

\author{
Jonas Holmberg ${ }^{1,2, a^{*}}$, Mikko Palosaari ${ }^{3, b}$, Seyed Hosseini ${ }^{1, c}$, Henri Larjosuo ${ }^{3, d}$ \\ and Pär Andersson ${ }^{1, e}$ \\ ${ }^{1}$ Swerea IVF AB, Argongatan 30, Mölndal SE-431 53, Sweden \\ ${ }^{2}$ University West, Dep. Of Engineering Science, Trolhättan SE-461 86, Sweden \\ ${ }^{3}$ Stresstech OY, Tikkutehtaantie 1 Fl-40800 Vaajakoski, Finland \\ ajonas.holmberg@swerea.se, ${ }^{b}$ mikko.palosaari@stresstech.com, cseyed.hosseini@swerea.se, \\ bhenri.larjosuo@stresstech.com, ${ }^{\mathrm{e}}$ par.andersson@swerea.se
}

Keywords: X-Ray Diffraction, Residual Stress, Round Robin, Measurement System Analysis

\begin{abstract}
Residual stress measurements using x-ray diffraction is a well established method used within the industrial and academic community to verify the performance of different processes for metallic materials. The measurement gives an absolute value of the stress state which can be used to design and optimize the process route to induce beneficial compressive residual stresses and avoid detrimental tensile stresses. Investigating the uncertainty and accuracy of the measurement system, operator and the material is therefore of high relevance both from an industrial and scientific point of view. Round robin testing is an important way to quantify the uncertainties that could affect the quality of the measured results and hence how a process is optimized and tuned. Such an investigation allows the operator to understand and reduce variations. Current round robin test includes results from five different laboratories using comparable equipments located in Sweden, Finland, Germany and United States. This work focuses on five shot-peened tool steel specimens produced with identical process settings. Additionally, an investigation of the repeatability of the system, influence of the operator, variations within the specimen, and the long time stability of the specimens has been measured.
\end{abstract}

\section{Introduction}

Residual stress measurements using x-ray diffraction is a well established and an essential method to study and verify the results from different processing operations of crystalline materials. This method is today a common practice both within the industrial and academic community. The absolute stress value allows studying how individual process steps affect the material. This opens up the opportunity of process optimization in such way to generate beneficial compressive residual stresses or minimize detrimental tensile stresses. This was for example shown by Matsumoto et al. who studied the influence of cutting parameters for case carburised bearing steels with a hardness of 58-62 HRC [1]. That investigation clearly showed the difference between a ground and a hard turned surface as well as how different cutting tools and parameters affected the stresses. Another example was shown by Kristoffersen et al. [2] who investigated the effect on the residual stresses from the induction hardening process parameters of a AISI 4340 steel. Residual stress measurements are also frequently used to study the impact from shot peening, which is strongly connected to the fatigue performance [3].

Considering that many components today are loaded close to their physical limitations, determination of residual stresses becomes even more important, where the reproducibility and

(c) (1) Content from this work may be used under the terms of the Creative Commons Attribution 3.0 license. Any further distribution of this work must maintain attribution to the author(s) and the title of the work, journal citation and DOI. Published under license by Materials Research Forum LLC. 
accuracy of the measurement becomes crucial. To capture the variation and scatter in the measurements, round robin activities are an important tool. Such an investigation evaluates the uncertainty and accuracy of the measurement system, operator and the material. A round robin investigation is therefore an important tool to be used both from an industrial and scientific point of view. Previously, one of the authors of this paper conducted a round robin study of carbon steel specimens under tensile stresses. That investigation showed that due to the stress state in the specimens, different source of variations could become more critical [4].

The French Association for residual stress analysis (GFAC) has been working with round robin analyses over a certain period of time, including several laboratories, different equipments and test materials [5]. A part of that investigation was presented for an Inconel 690 material which showed that the laboratories had a repeatability and a reproducibility of about $45 \mathrm{MPa}$ and $85 \mathrm{MPa}$ respectively. Connected to the same round robin study, Francois et al. [6] also evaluated a shot peened steel specimen, which they reported a standard deviation of the raw data from the different laboratories of $36 \mathrm{MPa}$. However, by analyzing the raw data with the same software and calculation settings the standard deviation was reduced to $18 \mathrm{MPa}$. Hence, it was clearly demonstrated the importance to correctly evaluate the raw data. On this topic Gibmeier et al. presented the results of a round robin for depth profiles of shot peened 42CrMo4 specimens [7]. That investigation showed even greater variation of the measured results from the different participating laboratories with standard deviation for the surface stress of $80 \mathrm{MPa}$ which was lowered to $40 \mathrm{MPa}$ after uniform evaluation, i.e. using same software.

A part of being an important way to quantify the uncertainties, round robin testing could also be a method to qualify new operators. This in turn could be compared to a measurement system analyses (MSA). However, when performing this there are a many factors that may affect the measurement, of which several are listed in the Measurement Good Practice Guide nr. 52 [8]. Some are related to the geometrical constrains of the specimen, and some are connected to the surface conditions, distribution of the stresses in the material, texture, and presence of coarse grains or high stress gradients. Other important aspects relate to how the measured data is analyzed, such as material properties used when calculating the stresses as well as which Peakfitting method that is used. Then there are a number of operator related factors that may greatly influence the result such as alignment of specimen relative equipment, selected measurement parameters such as exposure time measurements strategy and equipment alignment/calibration strategy. Evidently there are a great number of factors that needs to be considered when measuring the residual stresses using x-ray diffraction, and interestingly there are limited amount of published research work of round robin activities and how they are conducted. To better assess the quality of the as-obtained results, a deeper understanding of the large scatter in the repeatability and reproducibility of for example the results reported by GFAC is therefore necessary.

The aim of this investigation was to demonstrate the measurements uncertainties both in terms of variations from the measurement system, specimen itself as well as how different laboratories perform. For future repeatability measurements the long time stability of the specimens has also been evaluated with the intention to investigate if there is a decay or degradation with time.

\section{Material}

Several test specimens were manufactured from a cold work tool steel which was heat treated to a hardness of 45 HRC. The specimens were shot peened (full coverage) using steel balls with a size specified by SAE S170. All test specimens were shot peened at the same occasion using same parameters. Figure 1 illustrates one of the specimens (1033), and the two main measurement directions. 


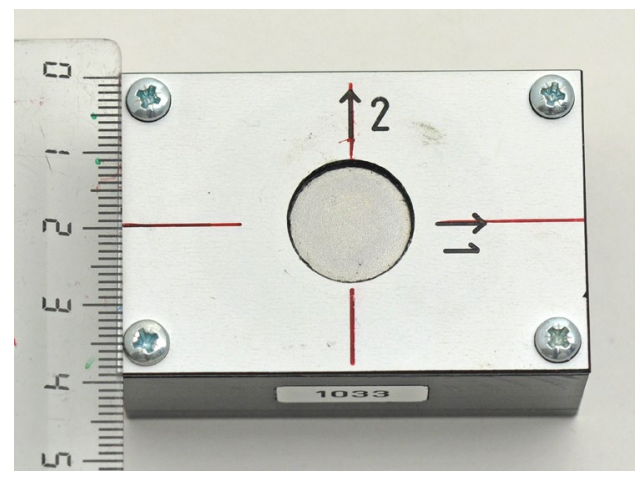

Figure 1. Overview of specimen 1033 defining measurement direction 1 and 2.

\section{Experimental}

This study has been divided into three major subparts; i) measurement system accuracy (MSA), ii) long time repeatability of test specimens and iii) round robin study. Throughout all measurements, a chromium x-ray tube was used and the modified $\chi$ method was employed as measurement principle. In this method the specimen is rotated about the $\chi$ axis, plane normal to that containing $\omega$ and $2 \omega$, further described in the standard EN-SS 15305:2009 [9]. Further, the (211) diffraction plane was deployed $\left(156.4^{\circ}\right)$. The residual stresses was calculated using Hook's law, assuming elastic strain theory, with a Young's modulus of $211 \mathrm{GPa}$ and 0.3 in Poisson's ratio. For the MSA analyses only one portable X-ray system was used, XStress 3000 G2R from Stresstech, with a $2 \mathrm{~mm}$ collimator and $5 \psi$-angles in the interval of $\pm 45^{\circ}$. The long time repeatability measurements were performed with eight different Xstress 3000 diffractometers, including G2R, G3 and Robot systems by eight operators using 1-3 mm collimators. For the round robin study the different laboratories used XRD systems such as Xstress 3000 G2R, Xstress 3000 G3 and as well as stationary systems Mahle, Bruker. The round robin measurements were repeated three times (in two direction 1 and 2). It should be noted that aside from performing multiple measurement in the same setup, the samples were even repositioning for each measurement. The specimen was aligned according to the indicators on the specimens, see Figure 1 (arrows on the

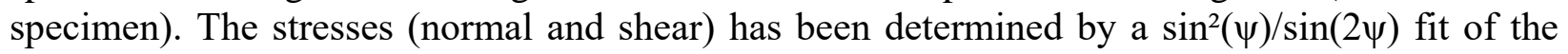
determined peak positions (or the strain values calculated from them).

\section{Results and discussion}

\section{Measurement systems analysis}

The intention with this MSA was to study how individual equipment performed in order to compare this in relation to the round robin investigation. In this case one of the participating laboratories performed the measurements with a X3000 G2R system. This investigation was three folded to study variation from a) the specimen, b) the measurement system and c) the operator. In a) measurements were performed at five different locations on the specimen with a displacement by $1.5 \mathrm{~mm}$. Table 1 shows the results, where the standard deviation was $6.5 \mathrm{MPa}$, or $1.1 \%$. The deviation, dev, is the results from the peak fitting using cross correlation and constant background. For b) the measurements were repeated without moving the specimen or altering the measurement settings. The variation from the equipment, shown in Table 1, resulted in a standard deviation of $2.6 \mathrm{MPa}$ or $\pm 0.4 \%$. For c) two operators were included, where measurements were performed by repositioning the specimen between each measurement (removing and repositioning the specimen in the specimen holder). Each operator measured five times, with the target to measure the stresses at the centre of the specimen. The result in Table 2 shows comparable values and a standard deviation of $1.8 \mathrm{MPa}$ and $3.1 \mathrm{MPa}$ for operator 1 and 2.

The MSA results show that the major factors contributing the variation come from the specimen itself and from raw data calculation of the peak fitting according to Table 1-2. In this case, cross correlation with a constant background was employed for peak fitting resulting in a standard deviation of 7.1 MPa. The total measurement uncertainty from this system, calculated as the root mean square of the different factors, a), b), c) and peak fitting, resulted in a value of 10.2 MPa. This result is in line with the results presented by François et al. [6]. That 
investigation further identified that the operator had a strong influence on the result which in turn also will be influenced by variation in the specimen and specimen alignment.

Table 1. Results from sample and equipment repeatability measurements on specimen 1033.

\begin{tabular}{|c|c|c|c|c|c|c|c|c|c|}
\hline \multicolumn{5}{|c|}{ a) Specimen influence } & \multicolumn{5}{|c|}{ b) Equipment repeatability } \\
\hline Position & $\begin{array}{c}\text { Direction } 1 \\
{[\mathrm{MPa}]} \\
\end{array}$ & $\begin{array}{c}\mathrm{Dev} \\
{[\mathrm{MPa}]}\end{array}$ & $\begin{array}{c}\text { Direction } 2 \\
{[\mathrm{MPa}]}\end{array}$ & $\begin{array}{c}D e v \\
{[\mathrm{MPa}]}\end{array}$ & $\begin{array}{l}\text { Measurement } \\
\text { no. }\end{array}$ & $\begin{array}{c}\text { Direction } 1 \\
{[\mathrm{MPa}]}\end{array}$ & $\begin{array}{c}\mathrm{Dev} \\
{[\mathrm{MPa}]}\end{array}$ & $\begin{array}{c}\text { Direction } 2 \\
\text { [MPa] }\end{array}$ & $\begin{array}{c}\text { Dev } \\
{[\mathrm{MPa}]}\end{array}$ \\
\hline 1033_1 & -611.4 & 1.9 & -614.9 & 3.1 & $\# 1$ & -585 & 7 & -590 & 3.8 \\
\hline 1033_2 & -618.2 & 2.4 & -605.1 & 2.9 & \#2 & -588.6 & 7.7 & -592.2 & 3.1 \\
\hline $1033 \_3$ & -601.4 & 2.9 & -617.5 & 4.3 & \#3 & -586.1 & 7 & -585 & 3.4 \\
\hline $1033 \_4$ & -609.4 & 2.9 & -609 & 4.5 & \#4 & -583.4 & 7.1 & -589.7 & 3.2 \\
\hline $1033 \_5$ & -604.3 & 4.7 & -602.3 & 3.1 & \#5 & -585 & 6.5 & -589.6 & 4 \\
\hline Average [MPa] & -608.9 & 2.96 & -609.8 & 3.6 & Average [MPa] & -585.6 & 7.1 & -589.3 & 3.5 \\
\hline Std. Dev. [MPa] & 6.5 & & 6.4 & & Std. Dev. [MPa] & 1.9 & & 2.6 & \\
\hline Std. Dev. [\%] & 1.1 & & 1.1 & & Std. Dev. [\%] & 0.3 & & 0.4 & \\
\hline
\end{tabular}

Table 2. Results from operator influence for five repetitions and alignment on specimen 1033.

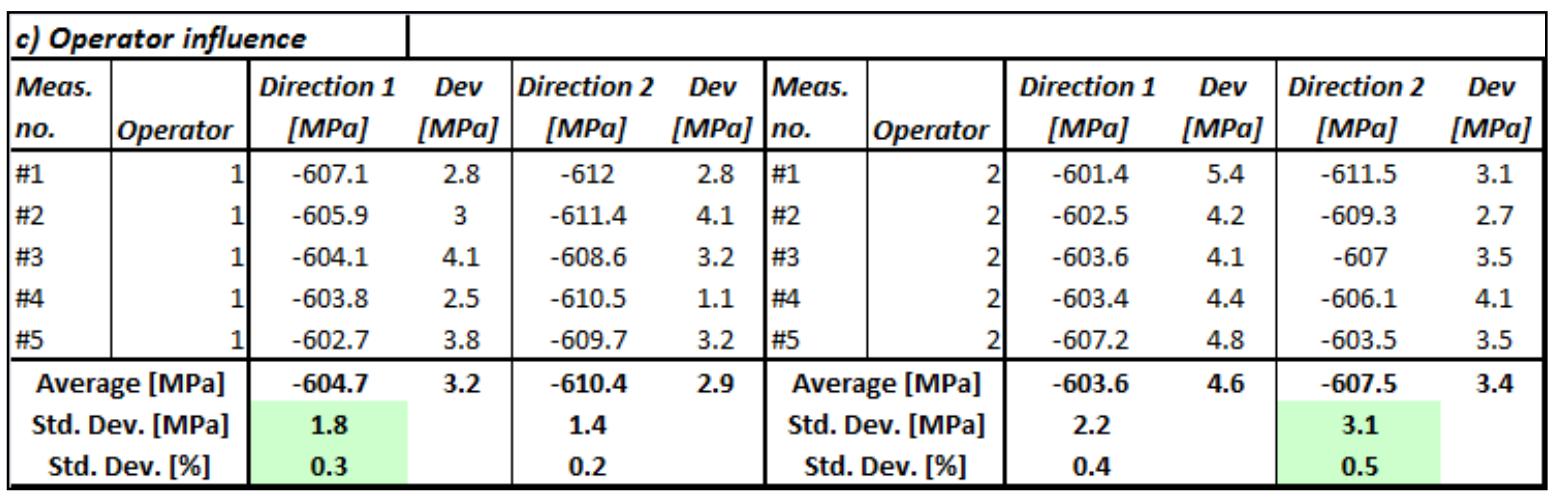

The purpose of the MSA was to elucidate the influence from other factors when performing the round robin investigation hence the results are therefore considered as generalized for this specimen. However, for a more geometrically complex test specimen, or a specimen where the stress distribution varies, the operator alignment procedure becomes critical which will be reflected in the repeatability. It is further suggested that this type of approach is adopted for new measurement objects in order to retrieve a general value of the expected uncertainty. This result should then be presented along with the measured absolute value, which might not be the case today since these systems typically only give the operator the deviation from the peak fitting.

\section{Long time repeatability of the specimens}

Two specimens (1021 and 1022), fabricated in the same batch as the round robin specimens, have additionally been used to analyze the long time repeatability by one of the participant laboratories. Roughly once a week, the specimens were measured with different diffractometers, in total by eight different operators. During 2.5 year period the specimen 1021 was measured 154 times and 106 times for specimen 1022. The results of the long term repeatability are shown in Figure 2 where the measured stress values in direction 1 are plotted as a function of measurement date. The error bars on the graph are the measured 1-sigma deviation of the fitting routine for each measured residual stress value. The average for all of the values were; $\sigma_{1021}=-593 \pm 10$ $\mathrm{MPa}$, and $\sigma_{1022}=-595 \pm 10 \mathrm{MPa}$, where the uncertainty is one sigma standard deviation.

A linear function was fitted on the results and a slope can be observed, -4.7 MPa /year for specimen 1021 and -1.7 MPa / year for specimen 1022. The reason for this gradual change of specimen 1021 might either be due to wear of the specimen in combination with the rapidly changing residual stress profile of these specimens. It might also be due to drift in the equipment. The maximum compressive stress is located below the surface and the residual stress profiles in 
this case showed a positioning at about $50 \mu \mathrm{m}$ below surface. If the surface wears down the measured stresses might be affected. This could be an important factor to consider when designing and producing new reference specimens. It might be a good approach to generate a profile that has similar stress state in the surface and below the surface that take height for any future wear of the specimen. However, further measurements need to be carried out to see if this trend continues. For the other sample the change is less than 1\% change per year.
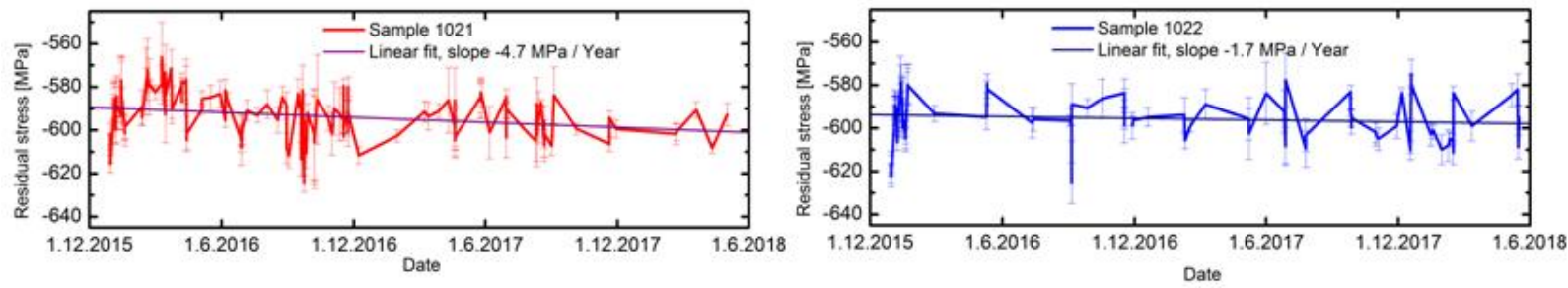

Figure 2. Long term repeatability of specimens 1021 and 1022.

\section{Round robin measurements}

The results from the round robin testing have been compared for each specimen and measurement direction in Figure 3. The results are the average values for the three measurements performed for each specimen by laboratory A-E and equipment _1-_4. Respectively, the error bars show the standard deviation for the three measurements. The dotted lines represent the minimum and maximum values including the standard deviation. The summarized result for these specimens lies within the interval (-)554 - (-)611 MPa with a average value of -590.4 MPa and a standard deviation of $10 \mathrm{MPa}$. Results from the different laboratories show that laboratory $\mathrm{D}$ measures the lowest average stress for all specimens while laboratory $\mathrm{C}$ measures the highest stresses. However, individual equipments within both laboratory D and E measures both lower and higher results compared to the other laboratories. This means that the individual equipments rather than the laboratories are generating the different results.

The average results for each specimen from the round robin measurements are summarised in Table 3 which show that the values from all laboratories and equipment is in the interval (-)583.9 - (-) $596.8 \mathrm{MPa}$ with a standard deviation of $11.1 \mathrm{MPa}$ as maximum and a $9.1 \mathrm{MPa}$ on an average which corresponds to $1.9 \%$ as maximum and $1.5 \%$ on an average.

Table 3. Result table of the average values from the round robin testing

\begin{tabular}{|c|c|c|c|c|c|c|c|c||}
\hline Specimen & Direction & $\begin{array}{c}\text { Mean } \\
{[\mathrm{MPa}]}\end{array}$ & $\begin{array}{c}\text { Std. Dev } \\
{[\mathrm{MPa}]}\end{array}$ & $\begin{array}{c}\text { Std. Dev } \\
{[\%]}\end{array}$ & Direction & $\begin{array}{c}\text { Mean } \\
{[\mathrm{MPa}]}\end{array}$ & $\begin{array}{c}\text { Std. Dev } \\
{[\mathrm{MPa}]}\end{array}$ & $\begin{array}{c}\text { Std. Dev } \\
{[\%]}\end{array}$ \\
\hline 1028 & 1 & -595.5 & 7.8 & 1.4 & 2 & -590.4 & 7.4 & 1.2 \\
\hline 1029 & 1 & -585.6 & 9.4 & 1.5 & 2 & -583.9 & 10.1 & 1.7 \\
\hline 1030 & 1 & -595.1 & 7.7 & 1.4 & 2 & -587.7 & 11.1 & 1.9 \\
\hline 1031 & 1 & -586.6 & 7.9 & 1.3 & 2 & -590.9 & 11.0 & 1.8 \\
\hline 1032 & 1 & -591.4 & 9.4 & 1.5 & 2 & -596.8 & 9.3 & 1.5 \\
\hline
\end{tabular}
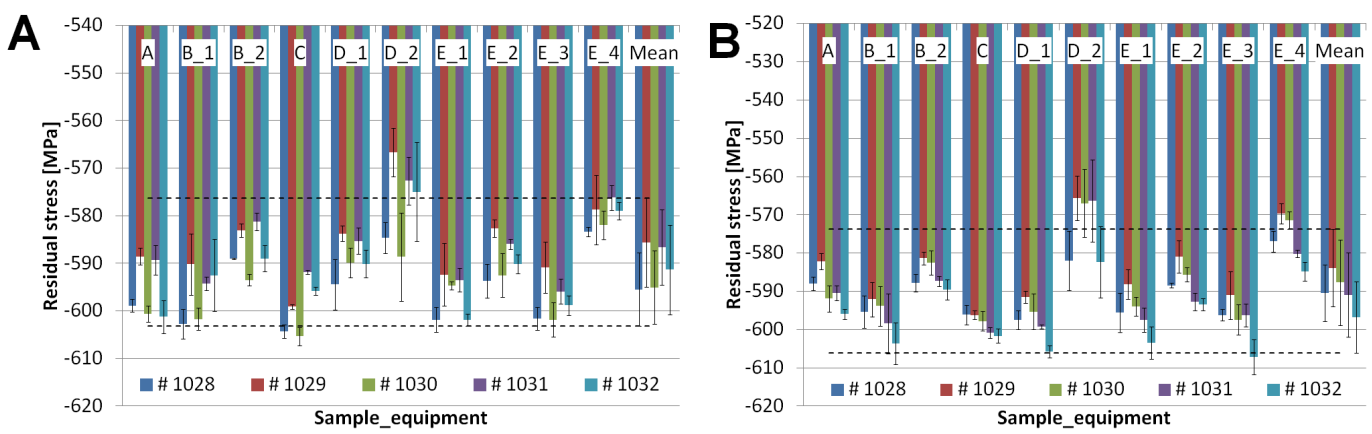

Figure 3. Result of the round robin surface residual stress measurements of the five shot peened specimens in direction 1 (A), and direction 2 (B). 


\section{Conclusions}

These results clearly show the systems-operator performance, the influence of the test specimen which in turn contributes to the performance of the round robin testing. It could however be difficult to exactly determine how different factors influence on the performance since many of them are linked. The following conclusions were drawn from these investigations:

- The measurement system analysis resulted in a total system uncertainty of $10.2 \mathrm{MPa}$ for this shot peened specimen. The peak fitting of raw diffraction data and variation in surface stress distribution are the most influential on the measurement uncertainty for the system.

- The long term stability of the specimens had a slight decay over the years of $-4.7 \mathrm{MPa} / \mathrm{year}$ for one specimen and -1.7 MPa / year for the other specimen.

- The round robin investigations showed very good repeatability with an average standard deviation of $\pm 9.1 \mathrm{MPa}$ corresponding to $\pm 1.5 \%$ for these measurement specimens.

- The round robin testing concluded that individual equipment rather than different laboratories influence the variation in the measured result.

\section{References}

[1] Y Matsumoto, F Hashimoto, G Lahoti, Surface Integrity Generated by Precision Hard Turning. CIRP Annals - Manufacturing Technology 48 (1999) 59-62.

https://doi.org/10.1016/S0007-8506(07)63131-X

[2] H Kristoffersen, P Vomacka, Influence of process parameters for induction hardening on residual stresses. Materials \& Design 22 (2001) 637-644. https://doi.org/10.1016/S02613069(01)00033-4

[3] S Wang, Y Li, M Yao, R Wang, Compressive residual stress introduced by shot peening. Journal of Materials Processing Technology 73 (1998) 64-73. https://doi.org/10.1016/S09240136(97)00213-6

[4] S B Hosseini, B Karlsson, T Vuoristo, K Dalaei, Determination of Stresses and Retained Austenite in Carbon Steels by X-rays - A Round Robin Study. Exp. Mech. 51 (2011) 59-69. https://doi.org/10.1007/s11340-010-9338-2

[5] F Lefebvre, E Wasniewski, M François, External Reference Samples for Residual Stress Analysis by X-Ray Diffraction. Advanced Materials Research 996 (2014) 221-227.

[6] M François, F Convert, S Branchu, French round-robin test of X-ray stress determination on a shot-peened steel. Experimental Mechanics 40 (2000) 361-368.

https://doi.org/10.1007/BF02326481

[7] J Gibmeier, J Lu, B Scholtes, Round Robin Test on the determination of residual stress depth distribution by X-ray diffrsction, Mat. Sci. Forum 404-407, 2002, pp. 659-664.

https://doi.org/10.4028/www.scientific.net/MSF.404-407.659

[8] M E Fitzpatrick, A Fry, P Holdway, Determination of residual stresses by X-ray diffraction. Measurement Good Practice Guide No 52 (2005).

[9] European Committee for Standardization, Non-destructive Testing - Test Method for Residual Stress analysis by X-ray Diffraction, EN-SS 15305:2009. 